\title{
Fair Allocation of Potential COVID-19 Vaccines Using an Optimization-Based Strategy
}

\author{
Aurora del Carmen Munguía-López ${ }^{1}$ - José María Ponce-Ortega ${ }^{1}$ (ib
}

Received: 16 September 2020 / Revised: 3 November 2020 / Accepted: 5 November 2020 / Published online: 13 January 2021

(C) Springer Nature Singapore Pte Ltd. 2021

\begin{abstract}
The fair allocation of resources among multiple stakeholders in any area is a complex challenge for decision-making. This paper presents an optimization strategy for the allocation of COVID-19 vaccines, when they are available, through different fairness schemes (social welfare, Nash, Rawlsian justice, and social welfare II scheme). The applicability of the proposed model is illustrated using the case study of Mexico, including the states of the country as stakeholders. We involve several parameters to guide the allocation, such as the size, risk profiles, and fraction of vulnerable groups in the population. Furthermore, different scenarios of the availability of potential COVID-19 vaccines were evaluated. The social welfare approach is the most commonly used scheme for the allocation of resources. However, we demonstrate that this scheme yields non-unique or multiple solutions (through the social welfare II approach). These social welfare approaches provide inequalities in the allocations that become critical when resources are scarce. Specifically, the social welfare scheme favors large stakeholders (greater population) in all scenarios. We also observe how the complexity of the allocation increases with the higher availability of vaccines. Hence, it is relevant to consider allocation schemes to identify fair solutions.
\end{abstract}

Keywords Optimization $\cdot$ COVID-19 $\cdot$ Vaccines $\cdot$ Allocation schemes $\cdot$ Mathematical modeling

\section{Introduction}

The first outbreak of severe acute respiratory syndrome (SARS) occurred 18 years ago. Since then, several SARSrelated coronaviruses (SARSr-CoVs) have been discovered in their natural reservoir host bats ( $\mathrm{Li}$ et al. 2005). Additionally, serological evidence related to the potential of bat SARSr-CoVs to infect humans has been presented (Wang et al. 2018). Recently, the identification and characterization of the new coronavirus, which caused the epidemic that started on 12 December 2019 in Wuhan, China, have been reported (Zhou et al. 2020). The World Health Organization informed about the official name of the infectious disease caused by this new virus: COVID-19 (WHO 2020a).

This article is part of the Topical Collection on COVID-19: optimization strategies to combat pandemic

José María Ponce-Ortega

jmponce@umich.mx

1 Chemical Engineering Department, Building V1, Universidad Michoacana de San Nicolás de Hidalgo, Ciudad Universitaria, Santiago Tapia S/N, 58060 Morelia, Michoacán, Mexico
COVID-19 is now a pandemic affecting many countries worldwide.

According to the WHO (WHO 2020b), most people recover from the disease without hospital treatment. However, 1 out of 5 patients became seriously ill and developed difficulty in breathing. Furthermore, it has been reported that the COVID19 case fatality rates are higher for vulnerable groups. These populations include the elderly and those with comorbid conditions, such as diabetes and hypertension ( $\mathrm{Wu}$ and McGoogan 2020). Unfortunately, for elderly patients with COVID-19, the probability of progressing to severe disease is higher, as well as mortality. The main cause of this is that elderly patients are more prone to multisystem organ dysfunction or even failure (Liu et al. 2020). Additionally, patients with pre-existing comorbidities are at higher risk of developing severe coronavirus infections than patients with a healthy medical history (Garg et al. 2020).

Problems in the allocation of medical resources have arisen worldwide due to the COVID-19 pandemic. For instance, a shortage of N-95 masks for health workers in the USA occurred. This shortage led to the reuse of these masks that are designed for single use. Additionally, in Italy, physicians have proposed giving priority of intensive care beds and ventilators 
to patients who can benefit more. Strategies for the allocation of resources in pandemics have been proposed previously. These strategies include four ethical values: (1) maximizing the benefits, (2) treating inhabitants equally, (3) promoting and rewarding instrumental value, and (4) giving priority to the worst-off. Overall, fair allocation needs a multivalue ethical framework that may vary depending on the context (Emanuel et al. 2020). On the other hand, the allocation of resources is not typically considered in the decision-making process of medical cases until there is a shortage of healthcare resources. Therefore, when evaluating the allocation of scarce resources, it is key to consider the proportionality of care and distributive justice (Vergano et al. 2020). Similarly, human resource allocation for crisis conditions has been studied by Aviso et al. (2017). Here, a P-graph model for the optimal allocation of the workforce during natural disasters or new disease outbreaks was proposed.

The global allocation of potential COVID-19 vaccines is a critical concern that is currently being analyzed. The main goal would be to achieve an equitable distribution among all countries. However, this represents a great challenge. Researchers have been warning about the barriers to making vaccines for everyone and the possibilities that wealthy countries might hoard supplies. Even if enough vaccines were made, there is no law to force countries to share them. The Coalition for Epidemic Preparedness Innovations mentioned that there are no contracts yet on the principles for a fair allocation system. Furthermore, there is no global entity responsible for the logistics of the manufacturing of vaccines on a global scale (including orders and payments) (Khamsi 2020). Recently, the European Commission-backed Access to COVID-19 Tools Accelerator was launched. This initiative is devoted to the development and equitable allocation of potential vaccines and others. Several countries and philanthropies are willing to give financial support. Nevertheless, G20 states still need to join the initiative. The global allocation of vaccines and therapeutics should be fair but also health-driven. A health-driven allocation includes considering the size, distribution, and risk profiles of the population. Specifically, governments must develop strategies to ensure that when vaccines become available, they are distributed equitably and fairly among all their population (including vulnerable groups) (Bollyky et al. 2020). Moreover, when the COVID-19 vaccine is approved, new manufacturing sites would need to be built. These sites should be distributed worldwide to ensure equitable allocation (Mahase 2020). In addition, prompt availability in an efficient way that can be accessible or affordable to all must be a priority (Bassi and Hwenda 2020).

The landscape of COVID-19 vaccine research and development is as follows. By April 8, 2020, there were 115 vaccine candidates. Of these, 78 have been confirmed as active. Of the 78 projects, 73 are at exploratory or preclinical stages, while the most advanced candidates have moved into clinical development (phase 1). Seventy-two percent of the confirmed active vaccine candidates are being developed by private or industry developers. The rest are projects developed by the academia, public sector, and other non-profit organizations. Most vaccine developments have been made in North America, followed by China, Asia (excluding China), Australia, and Europe. There is no current public information about vaccine development in Africa or Latin America. Given the global effort and the urgency for speed, there is an indication that vaccines can be available by early 2021 (under emergency use) (Le et al. 2020).

While the COVID-19 vaccine is being approved, some governments (including Chile, Germany, Italy, the UK, and the USA) have suggested an alternative. Their proposal consists of using immunity passports, which are documents that certify an individual has been infected and is presumably immune to COVID-19. However, this implies important equitable and legal challenges. Moreover, at this point in the pandemic, there is not enough evidence that people who have recovered from COVID-19 are protected from a second infection. Regarding fairness, there is no guarantee that access to antibody testing would be equal for all (including vulnerable populations) (Phelan 2020).

The allocation of resources among multiple stakeholders is a relevant problem for decision-making. Recently, an axiomatic approach including different allocation schemes has been reported (Sampat and Zavala 2019). Here, the deficiencies and desirable properties of these fairness allocation approaches are analyzed. The allocation of resources is often done by maximizing the sum of individual utilities (total utility). This approach is known as the social welfare scheme. Some deficiencies of this scheme include obtaining multiple allocations that yield unfair solutions. Additionally, the allocations might not capture stakeholder scales properly. On the other hand, the Rawlsian justice scheme was proposed by Rawls (Rawls 1971). This approach allocates resources by maximizing the utility of the smallest stakeholder, which means providing the greatest benefit to the least well-off members of society. However, this scheme might identify non-unique solutions. Alternatively, Nash (Nash 1950) proposed an approach in which allocation is guided by maximizing the product of individual utilities. This approach is equivalent to maximizing the sum of the logarithms of the utilities. This formulation identifies unique solutions and captures stakeholder scales. Furthermore, a scheme to illustrate the multiple allocations that can be obtained by the social welfare approach was recently proposed (Munguía-López et al. 2019). This scheme is denoted as social welfare II, and it helps to identify the degenerate nature of the standard social welfare scheme. 
These schemes have been previously used through mathematical models to allocate resources in agricultural (water) and industrial systems (raw materials) (Munguía-López et al. 2019; Juárez-García et al. 2020). Furthermore, the social welfare approach has been used to allocate supply and demand in electricity markets (Zavala et al. 2017). On the other hand, in the allocation of scarce medical interventions, the concepts of some allocation schemes, including Rawlsian justice and the social welfare approach (also called utilitarianism), have been analyzed from an ethical point of view (Persad et al. 2009). Moreover, the Nash approach has been used to compare care delivery settings for older adults (Mendoza-Alonzo et al. 2020). Here, a multiobjective integer programming formulation was proposed.

Regarding healthcare allocation, the allocation of ambulances considering fairness elements through optimization models has been studied (Acuna et al. 2020). Here, the min-max strategy and the Nash scheme are compared, and new insights for policy regulations are given. Previously, for influenza pandemics, a simulation optimization model to distribute mitigation resources was proposed by Savachkin and Uribe (2012). Their model seeks to support dynamic resource distribution by minimizing the impact of ongoing and potential outbreaks. However, fairness measures have not been considered here. Moreover, a mathematical approach to predict the number of ICU patients, as well as the mortality rate under the COVID-19 emergency, has been proposed (Manca et al. 2020). Here, regression models were used to predict possible scenarios of the analyzed variables. Furthermore, Sy et al. (2020) recommended using optimization modeling techniques for medical supply allocation, especially in scarce scenarios.

Therefore, we propose a mathematical modeling approach to find optimal allocations that can be deemed fair according to a set of fundamental axioms. Specifically, we study the allocation of potential COVID-19 vaccines among multiple stakeholders under different availability scenarios. Through the proposed model, it is possible to identify various allocations given by the fairness schemes. Moreover, alternatives for the decision-making of allocations are highlighted. This formulation provides a first approach for the allocation strategy of vaccines so that it can be used when they become available. Notice that an approach involving different schemes (social welfare, Nash, Rawlsian justice, and social welfare II allocation) for the distribution of potential COVID-19 vaccines has not been addressed previously. Furthermore, as opposed to other optimization approaches that seek to maximize or minimize only one specific function subject to certain constraints to find tradeoff solutions, we propose to identify these solutions using allocation schemes. These schemes allow identifying several solutions so that, depending on a particular scenario, the most suitable solution can be selected.

\section{Problem Statement}

The addressed problem consists of finding the optimal allocation of potential vaccines for COVID-19 among distinct stakeholders. To do so, this work presents an optimization formulation that uses fairness schemes to find such allocations. These schemes include the social welfare, Nash, Rawlsian, and social welfare II approaches. The formulation is general and can be applied to any case study. However, to illustrate the applicability of the presented approach, we propose to apply the formulation to the case study of Mexico. Specifically, we consider the allocation among the states of Mexico. Note that the formulation can also be used for the allocation among cities or municipalities. For the addressed case study, the 32 states of the country are considered stakeholders, while distinct scenarios of availability of vaccines are analyzed. Different parameters that are characteristic of each state were included. Some of these parameters involve the population, the rate of cases, the available beds, and the mortality rate due to COVID-19. It is essential to account for these values to guide the allocation of vaccines. The resulting model is based on the superstructure depicted in Fig. 1. The solution to the problem involves finding the optimum allocated vaccines for each state through different allocation schemes. Note that the model is general and can be applied to different case studies by modifying the parameters. In addition to considering the states of Mexico for the case study, the municipalities can also be involved. On the other hand, countries could be included in the analysis to identify the worldwide allocation of potential vaccines.

Regarding the case study, information from the Mexican government and other references was used for the different parameters. The data related to COVID-19, such as the rate of cases or the mortality rate, are based on the reported cases until April 29, 2020. Figure 2 presents the fraction of the population of each state that is considered the most vulnerable to COVID-19. These vulnerable groups include the elderly population, adults with hypertension, diagnosed diabetes mellitus, and obesity. The mortality rate due to COVID-19 in these groups is shown in Table 1 . We can see that the highest rate is for the elderly population $\left(\mathrm{m}^{\mathrm{e}}\right)$, followed by adults with hypertension $\left(m^{\text {hy }}\right)$, diabetes $\left(m^{\mathrm{dm}}\right)$, and obesity $\left(m^{\mathrm{ob}}\right)$. Note that we do not involve combined risk rates (due to lack of information). However, we consider that if one individual is part of at least one vulnerable group, he is being considered. We observe that the population of the states is significantly different since the least populated state has less than $10 \%$ of the population of the most populated state. These data are presented in Table 2. Here, the cases and mortality rates due to COVID-19 for each state are also shown. In addition, the required parameters to estimate the COVID-19 patients who would require hospitalization but will not receive this service due to a lack of medical resources are reported. 
Fig. 1 Superstructure proposed for the allocation of potential vaccines among the different states in Mexico

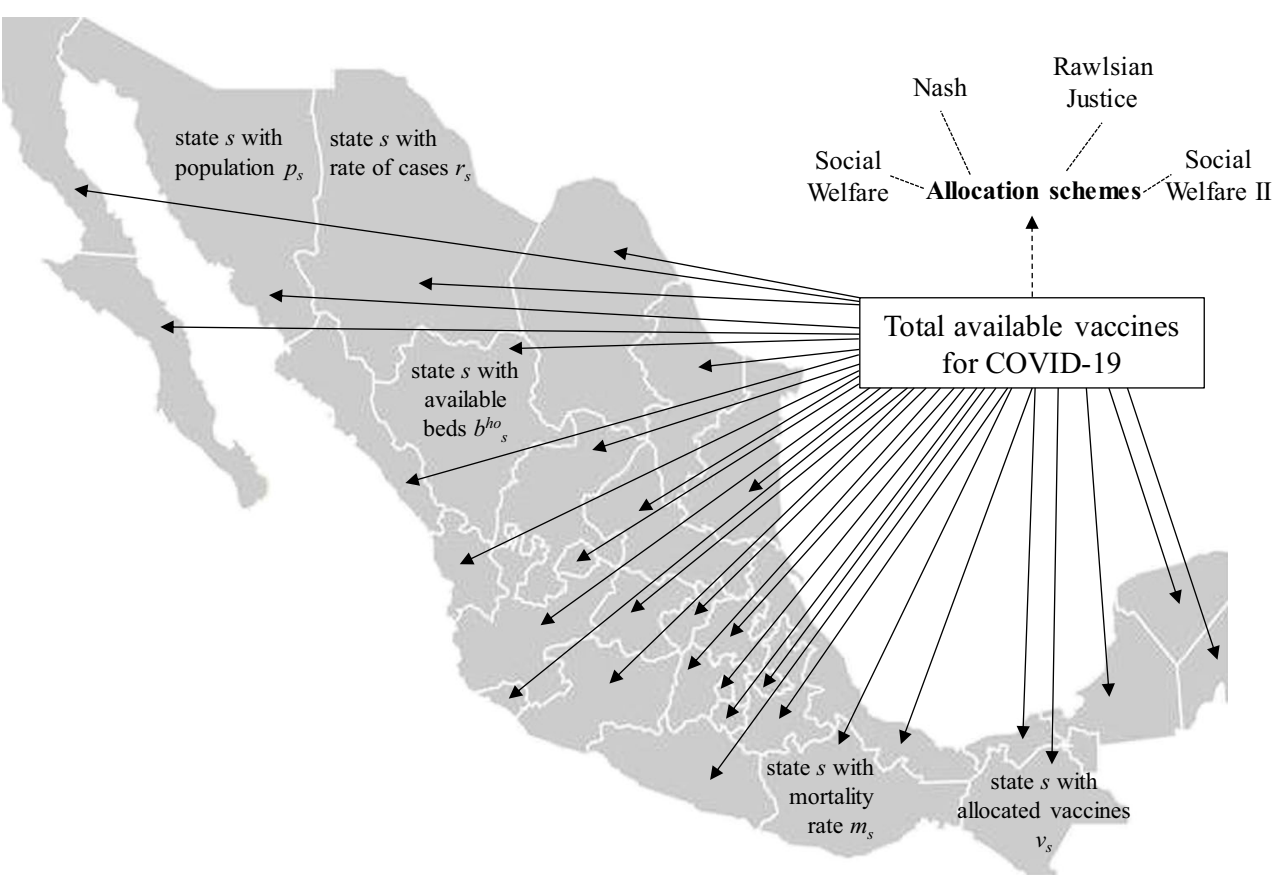

These parameters include the total available beds per state, as well as the discharged patients (of all diseases) and their average stay in a given year.

\section{Model Formulation}

To find the optimal allocation of potential vaccines among the states, different schemes were evaluated (social welfare, Nash, Rawlsian justice, and social welfare II scheme) through the mathematical model. The objective function of the model depends on the allocation scheme. Therefore, first, we present the equations that every formulation includes. Then, the objectives for each scheme are explained.

As shown in Eq. (1), the sum of the allocated vaccines to each state $s$ must be lower or equal than the total available vaccines (VT). Furthermore, Eqs. (2) and (3) are used to denote that the vaccines for each state $s$ must be lower or equal than the population $\left(p_{s}\right)$ and at least equal to a minimum threshold $\left(c_{s}\right)$. Note that when constraint (2) is active, the

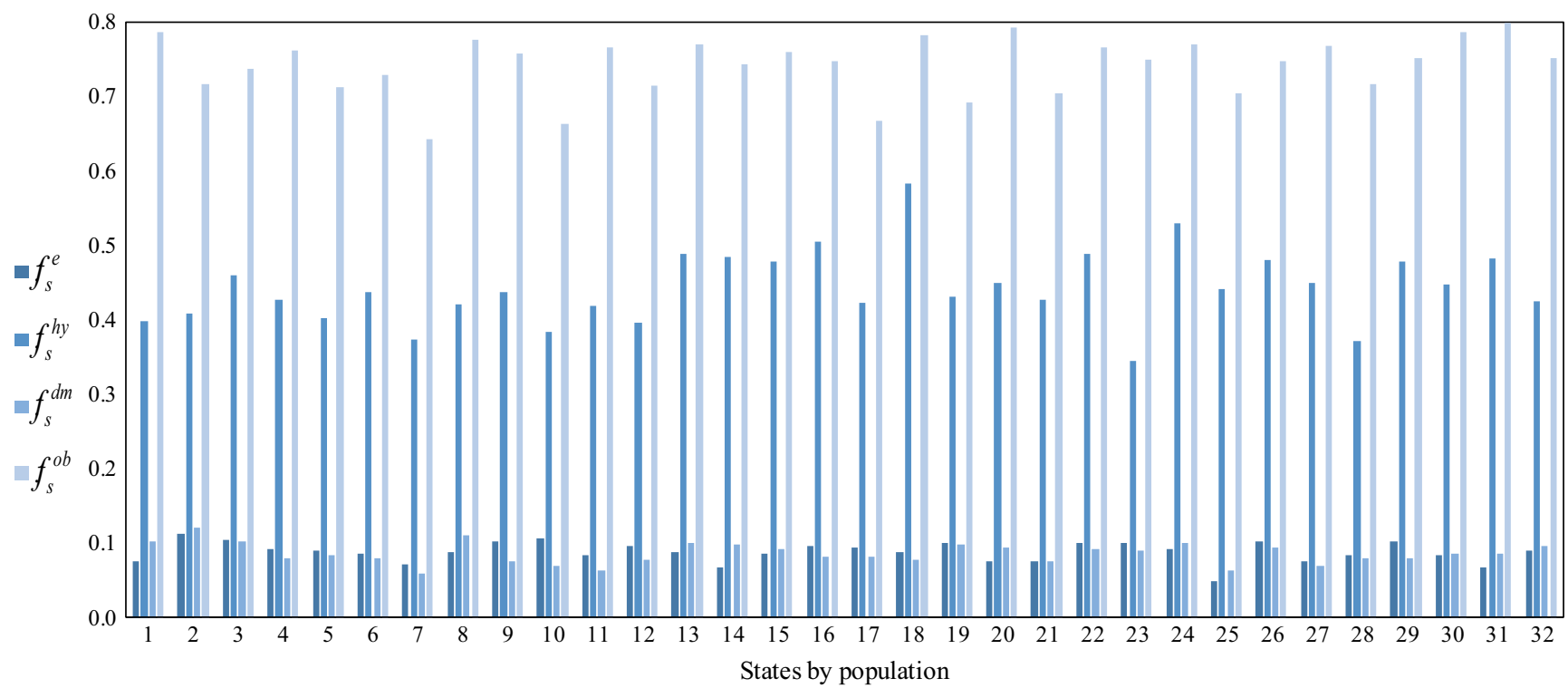

Fig. 2 Parameters for each state including the fraction of the elderly population $\left(f_{\mathrm{s}}^{\mathrm{e}}\right)$, the prevalence of hypertension in adults $\left(f^{\mathrm{hy}}\right)$, the prevalence of diagnosed diabetes mellitus in adults $\left(f^{\mathrm{dm}}\right)$, and the prevalence of obesity in adults $\left(f^{\mathrm{ob}}{ }_{\mathrm{s}}\right.$ ) (INEGI 2014; Barquera et al. 2010; Hernández-Ávila et al. 2013; Barquera et al. 2013) 
Table 1 Data including the mortality for the vulnerable groups to COVID-19 $\left(m^{\mathrm{e}}, m^{\mathrm{hy}}, m^{\mathrm{dm}}, m^{\mathrm{ob}}\right)$ as well as the fraction of COVID-19 patients who require hospitalization $\left(f^{\text {h }}\right)$ and the occupancy index in hospitals $\left(i^{\circ}\right)$ (UISP 2020; DGE 2020; Quesada 2009)

\begin{tabular}{llllll}
\hline$m^{\mathrm{e}}$ & $m^{\text {hy }}$ & $m^{\mathrm{dm}}$ & $m^{\text {ob }}$ & $f^{\text {h }}$ & $i^{\mathrm{o}}$ \\
\hline $4.81 \mathrm{E}-01$ & $4.27 \mathrm{E}-01$ & $3.99 \mathrm{E}-01$ & $3.00 \mathrm{E}-01$ & $3.96 \mathrm{E}-01$ & $8.50 \mathrm{E}-01$
\end{tabular}

maximum vaccines are allocated to each state. On the other hand, when constraint (3) is active, the minimum vaccines are allocated to each state.

$\sum_{s \in S} v_{s} \leq V T$

$v_{s} \leq p_{s}, \quad s \in S$

$v_{s} \geq c_{S}, \quad s \in S$
The threshold of Eq. (3) is a parameter that varies for each state. This threshold refers to the minimum amount of population that should receive a vaccine. We include this constraint to establish a lower bound for the allocation that allows taking into account the population at higher risk. Therefore, as shown in Eq. (3), the allocated vaccines must be greater or equal than the threshold. We estimate this threshold as shown in Eq. (4). Here, the COVID-19 patients who would require hospitalization but will not receive this service due to a lack of medical resources $\left(b_{s}\right)$ are considered. Additionally, the COVID-19 mortality rate is considered $\left(m_{s}\right)$ and the most vulnerable groups to COVID-19. These groups include the elderly, as well as the population with an underlying condition such as obesity, hypertension, and diabetes mellitus. The mortality rate due to COVID-19 in these groups $\left(m^{\mathrm{e}}, m^{\mathrm{ob}}, m^{\text {hy }}, m^{\mathrm{dm}}\right.$ ) and the fraction of the population that is part of these
Table 2 Parameters for each state including population $\left(p_{s}\right)$, rate of COVID-19 cases $\left(r_{\mathrm{s}}\right)$, and COVID-19 mortality rate $\left(m_{s}\right)$, as well as available beds $\left(b^{\text {ho }}\right)$, discharged patients $\left(d^{\mathrm{p}}{ }_{s}\right)$, and the average stay of patients in days $\left(s_{s}^{\mathrm{a}}\right)$ for all diseases. The information related to COVID-19 is based on the reported cases until April 29, 2020 (DGE 2020; SINAISCAP 2020)

\begin{tabular}{|c|c|c|c|c|c|c|c|}
\hline \multicolumn{2}{|c|}{ States by population } & \multirow{2}{*}{$\frac{p_{s}}{17,427,790}$} & \multirow{2}{*}{$\frac{r_{s}}{1.64 \mathrm{E}-04}$} & \multirow{2}{*}{$\begin{array}{l}m_{s} \\
7.33 \mathrm{E}-02\end{array}$} & \multirow{2}{*}{$\frac{b_{s}^{\text {ho }}}{8356}$} & \multirow{2}{*}{$\frac{d_{s}^{\mathrm{p}}}{303,939}$} & \multirow{2}{*}{$\frac{s_{s}^{\mathrm{a}}}{4.3}$} \\
\hline 1 & Estado de Mexico & & & & & & \\
\hline 2 & Ciudad de Mexico & $9,018,645$ & $5.30 \mathrm{E}-04$ & $6.71 \mathrm{E}-02$ & 15,632 & 249,752 & 5.7 \\
\hline 3 & Veracruz & $8,539,862$ & $6.02 \mathrm{E}-05$ & $8.56 \mathrm{E}-02$ & 4999 & 163,327 & 3.5 \\
\hline 4 & Jalisco & $8,409,693$ & $3.88 \mathrm{E}-05$ & $7.66 \mathrm{E}-02$ & 6460 & 176,843 & 4.1 \\
\hline 5 & Puebla & $6,604,451$ & $9.40 \mathrm{E}-05$ & $1.35 \mathrm{E}-01$ & 4012 & 118,039 & 4.4 \\
\hline 6 & Guanajuato & $6,228,175$ & $3.84 \mathrm{E}-05$ & $9.20 \mathrm{E}-02$ & 3657 & 158,514 & 3.7 \\
\hline 7 & Chiapas & $5,730,367$ & $2.88 \mathrm{E}-05$ & $4.24 \mathrm{E}-02$ & 2260 & 108,258 & 3.3 \\
\hline 8 & Nuevo Leon & $5,610,153$ & $5.58 \mathrm{E}-05$ & $3.83 \mathrm{E}-02$ & 4077 & 54,699 & 3.7 \\
\hline 9 & Michoacán & $4,825,401$ & $5.76 \mathrm{E}-05$ & $1.30 \mathrm{E}-01$ & 2648 & 100,186 & 2.6 \\
\hline 10 & Oaxaca & $4,143,593$ & $3.14 \mathrm{E}-05$ & $1.38 \mathrm{E}-01$ & 2352 & 76,420 & 3.5 \\
\hline 11 & Chihuahua & $3,801,487$ & $8.55 \mathrm{E}-05$ & $2.12 \mathrm{E}-01$ & 2915 & 81,911 & 4.1 \\
\hline 12 & Guerrero & 3657,048 & $7.33 \mathrm{E}-05$ & $1.83 \mathrm{E}-01$ & 2075 & 78,186 & 3.2 \\
\hline 13 & Tamaulipas & $3,650,602$ & $8.44 \mathrm{E}-05$ & $5.84 \mathrm{E}-02$ & 2977 & 77,266 & 3.8 \\
\hline 14 & Baja California & $3,634,868$ & $4.11 \mathrm{E}-04$ & $1.42 \mathrm{E}-01$ & 2153 & 40,627 & 4.5 \\
\hline 15 & Coahuila & $3,218,720$ & $1.15 \mathrm{E}-04$ & $1.11 \mathrm{E}-01$ & 2915 & 39,205 & 3.7 \\
\hline 16 & Sinaloa & $3,156,674$ & $2.60 \mathrm{E}-04$ & $1.62 \mathrm{E}-01$ & 2382 & 54,142 & 3.9 \\
\hline 17 & Hidalgo & $3,086,414$ & $7.84 \mathrm{E}-05$ & $1.12 \mathrm{E}-01$ & 1367 & 56,521 & 4.2 \\
\hline 18 & Sonora & $3,074,745$ & $6.57 \mathrm{E}-05$ & $1.09 \mathrm{E}-01$ & 2894 & 90,264 & 2.9 \\
\hline 19 & San Luis Potosi & $2,866,142$ & $3.42 \mathrm{E}-05$ & $7.14 \mathrm{E}-02$ & 2021 & 60,832 & 4 \\
\hline 20 & Tabasco & $2,572,287$ & $3.66 \mathrm{E}-04$ & $1.24 \mathrm{E}-01$ & 1583 & 81,367 & 2.9 \\
\hline 21 & Queretaro & $2,279,637$ & $5.61 \mathrm{E}-05$ & $7.82 \mathrm{E}-02$ & 881 & 51,749 & 3.2 \\
\hline 22 & Yucatan & $2,259,098$ & $1.79 \mathrm{E}-04$ & $6.44 \mathrm{E}-02$ & 1800 & 53,173 & 4.3 \\
\hline 23 & Morelos & $2,044,058$ & $1.36 \mathrm{E}-04$ & $1.12 \mathrm{E}-01$ & 1047 & 44,348 & 2.7 \\
\hline 24 & Durango & $1,868,996$ & $3.10 \mathrm{E}-05$ & $1.04 \mathrm{E}-01$ & 1542 & 48,582 & 2.6 \\
\hline 25 & Quintana Roo & $1,723,259$ & $4.13 \mathrm{E}-04$ & $1.53 \mathrm{E}-01$ & 1030 & 40,320 & 3.6 \\
\hline 26 & Zacatecas & $1,666,426$ & $4.20 \mathrm{E}-05$ & $1.00 \mathrm{E}-01$ & 999 & 38,496 & 3.4 \\
\hline 27 & Aguascalientes & $1,434,635$ & $1.29 \mathrm{E}-04$ & $1.08 \mathrm{E}-02$ & 966 & 39,160 & 3.3 \\
\hline 28 & Tlaxcala & $1,380,011$ & $1.30 \mathrm{E}-04$ & $1.01 \mathrm{E}-01$ & 714 & 54,655 & 2.2 \\
\hline 29 & Nayarit & $1,288,571$ & $5.59 \mathrm{E}-05$ & $1.67 \mathrm{E}-01$ & 714 & 19,665 & 2.8 \\
\hline 30 & Campeche & $1,000,617$ & $8.69 \mathrm{E}-05$ & $1.96 \mathrm{E}-01$ & 790 & 24,245 & 3.9 \\
\hline 31 & Baja California Sur & 804,708 & $3.74 \mathrm{E}-04$ & $5.32 \mathrm{E}-02$ & 695 & 19,639 & 3.2 \\
\hline 32 & Colima & 785,153 & $3.31 \mathrm{E}-05$ & $1.15 \mathrm{E}-01$ & 649 & 19,049 & 3.5 \\
\hline
\end{tabular}


vulnerable groups are also involved $\left(f_{s}^{\mathrm{e}}, f^{\mathrm{ob}}, f_{s}^{\mathrm{hy}}, f^{\mathrm{dm}}{ }_{s}\right) . r_{s}$ refers to the rate of COVID-19 cases per state. For the rate of cases, we involve a factor based on the sentinel surveillance technique as an attempt to make a closer estimation of the actual number of cases (Torres Ramírez 2020; LazcanoPonce and Alpuche-Aranda 2020). By combining these different parameters, we represent the minimum threshold for the allocated vaccines that seek to guarantee that the population at higher risk is covered in the allocation. Note that this threshold varies depending on the particular parameters of each state. For instance, as presented in Fig. 2 (see the "Problem Statement" section), the fraction of the prevalence of obesity in adults is the highest for state 31 , while the fraction of the prevalence of hypertension in adults is the highest for state 18 .

$c_{s}=b_{s}$

$$
+p_{s} r_{s}\left(m_{s}+m^{\mathrm{e}} f_{s}^{\mathrm{e}}+m^{\mathrm{ob}} f_{s}^{\mathrm{ob}}+m^{\mathrm{hy}} f_{s}^{\mathrm{hy}}+m^{\mathrm{dm}} f_{s}^{\mathrm{dm}}\right), s \in S
$$

The demand for hospital beds for COVID-19 patients that cannot be satisfied is denoted by $b_{s}$. This demand is estimated considering the fraction of COVID-19 patients who required hospitalization $\left(f^{\mathrm{h}}\right)$ plus the beds that are required per year in each state for other diseases minus the available beds per state. The beds that are required per year in each state for other diseases were estimated by using the Brigdman formula (Quesada 2009).

$b_{s}=p_{s} r_{s} f^{\mathrm{h}}+\frac{d_{s}^{\mathrm{p}} s_{s}^{\mathrm{a}}}{d^{\mathrm{y}} i^{\mathrm{o}}}-b_{s}^{\mathrm{ho}}, s \in S$

Note that $c_{s}$ and $b_{s}$ are parameters in the model. We specified how they are estimated and the involved data to show the considerations that are taken into account for the proposed formulation.

As mentioned above, the objective function and the type of model vary depending on the allocation scheme that is selected. For the social welfare and Rawlsian justice schemes, the resulting models are linear programs (LP). On the other hand, for the Nash and social welfare II approaches, the models are non-linear programs (NLP).

For the social welfare scheme, the following objective is used to allocate the vaccines. This scheme seeks to maximize the total vaccines of all states.

$$
\begin{aligned}
& \max \sigma^{\mathrm{SW}} \\
& \sigma^{\mathrm{SW}}=\sum_{s \in S} v_{s}
\end{aligned}
$$

The objective function of the Nash scheme is modeled by the following formulation:

$\max \sigma^{\mathrm{N}}$
$\sigma^{\mathrm{N}}=\sum_{s \in S} \log v_{s}$

For the Rawlsian justice scheme, the smallest allocated vaccines are maximized as presented in the following equations:

$\min \sigma^{\mathrm{R}}$

$-v_{s} \leq \sigma^{\mathrm{R}}, \quad s \in S$

The social welfare II scheme was previously proposed to illustrate the multiple solutions that the social welfare approach has (Munguía-López et al. 2019). We include this formulation as shown in the following. We can see that this scheme seeks an alternative allocation that is equal to the total allocated vaccines by the social welfare approach $\left(v^{\mathrm{sw}}{ }_{s}\right)$.

$\max \sigma^{S I I}$

$\sigma^{\mathrm{SII}}=\sum_{s \in S}\left(v_{s}-v_{s}^{\mathrm{SW}}\right)^{2}$

$\sum_{s \in S} v_{s}=\sum_{s \in S} v_{s}^{\mathrm{SW}}$

\section{Results}

Several scenarios for the total available vaccines (VT) were considered: (a) $0.1 \%$, (b) $4 \%$, (c) $8 \%$, (d) $12 \%$, (e) $16 \%$, and (f) $32 \%$ of the total population of Mexico. First, we observe that when the total available vaccines are minimal (scenario (a)), all the schemes allocate the minimum vaccines to each state (equal to the threshold). However, as the number of total vaccines increases, different solutions are found by each allocation scheme. Figure 3 shows the allocations for scenario (b). Here, we observe that the social welfare scheme gives preference to state 1 and allocates the minimum to the other states. The social welfare II scheme provides a similar allocation, but it gives preference to state 6 . Note that almost the same amount of vaccines is allocated to states 1 and 6 by these different schemes. This solution illustrates how, despite having the same constraint for the availability of vaccines, multiple solutions can be obtained through the social welfare approach. On the other hand, the Nash and Rawlsian schemes give the same solution. These schemes allocate the minimum to each state (equal to the threshold), and then, the remaining vaccines are allocated equally among all states.

Then, for scenario (c) of availability, the allocated vaccines to each state are presented in Fig. 4. Again, the Nash and Rawlsian schemes allocate an equal number of vaccines for each state (higher than in scenario (b) due to the higher availability). However, the social welfare approach keeps giving preference to state 1 . Now, this scheme allocates a number of vaccines higher than half the population of this state. The 


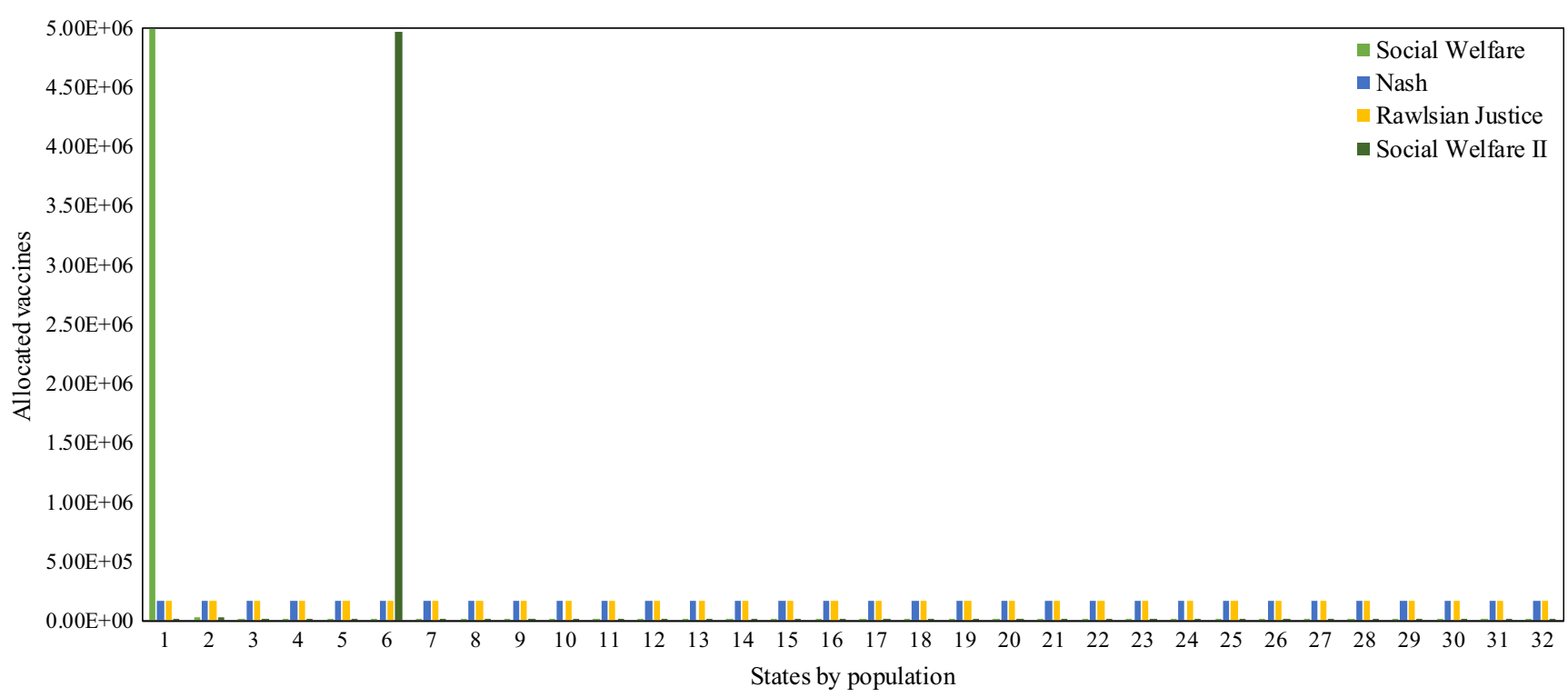

Fig. 3 Allocated vaccines under different allocation schemes (scenario (b) of availability)

social welfare II scheme gives preference to states 2 and 3 . However, the main preference is for state 2 since the allocated vaccines are equal to its population. In scenario (d), where the availability of vaccines increases to $12 \%$, the trends of all schemes are similar (see Fig. 5). The only variation for the Nash and Rawlsian approaches is that more vaccines are allocated to every state, but again, in an equal amount. For the social welfare scheme, more vaccines are allocated to state 1 . In the social welfare II scheme, the same vaccines to state 2 as in scenario (c) are allocated. However, the vaccines assigned to state 3 increase to more than half the population of this state.

On the other hand, when scenario (e) is considered (vaccine availability is $16 \%$ of the total population), the allocation varies for the social welfare schemes (see Fig. 6). For the social welfare approach, we observe that it favors both states 1 and 2. Here, the maximum amount of vaccines for state 1 is allocated (equal to its population), and the rest is allocated to state 2 . The social welfare II scheme gives the most preference to states 3 and 4 (allocated vaccines are equal to its population); it also favors state 5 but with fewer vaccines. For the Nash and Rawlsian schemes, the allocation keeps giving preference to all states equally.

In Fig. 7, the allocations for scenario (f) are presented. Here, the availability of vaccines increases to $32 \%$. Since the amount of available vaccines is twice greater than in scenario (e), the complexity of the allocation increases. Therefore, different allocations are found with each scheme. For the social welfare approach, the maximum vaccines for states 1,2 , and 3

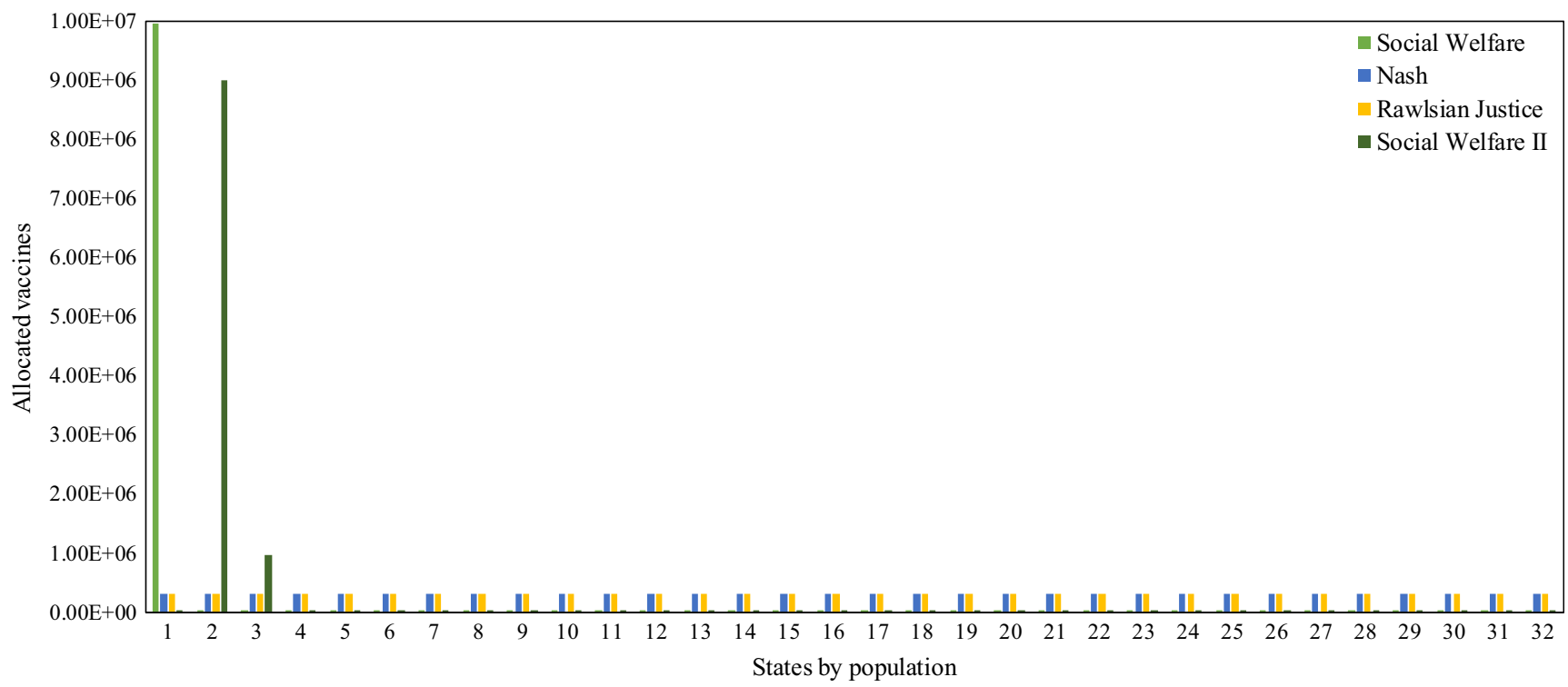

Fig. 4 Allocated vaccines under different allocation schemes (scenario (c) of availability) 


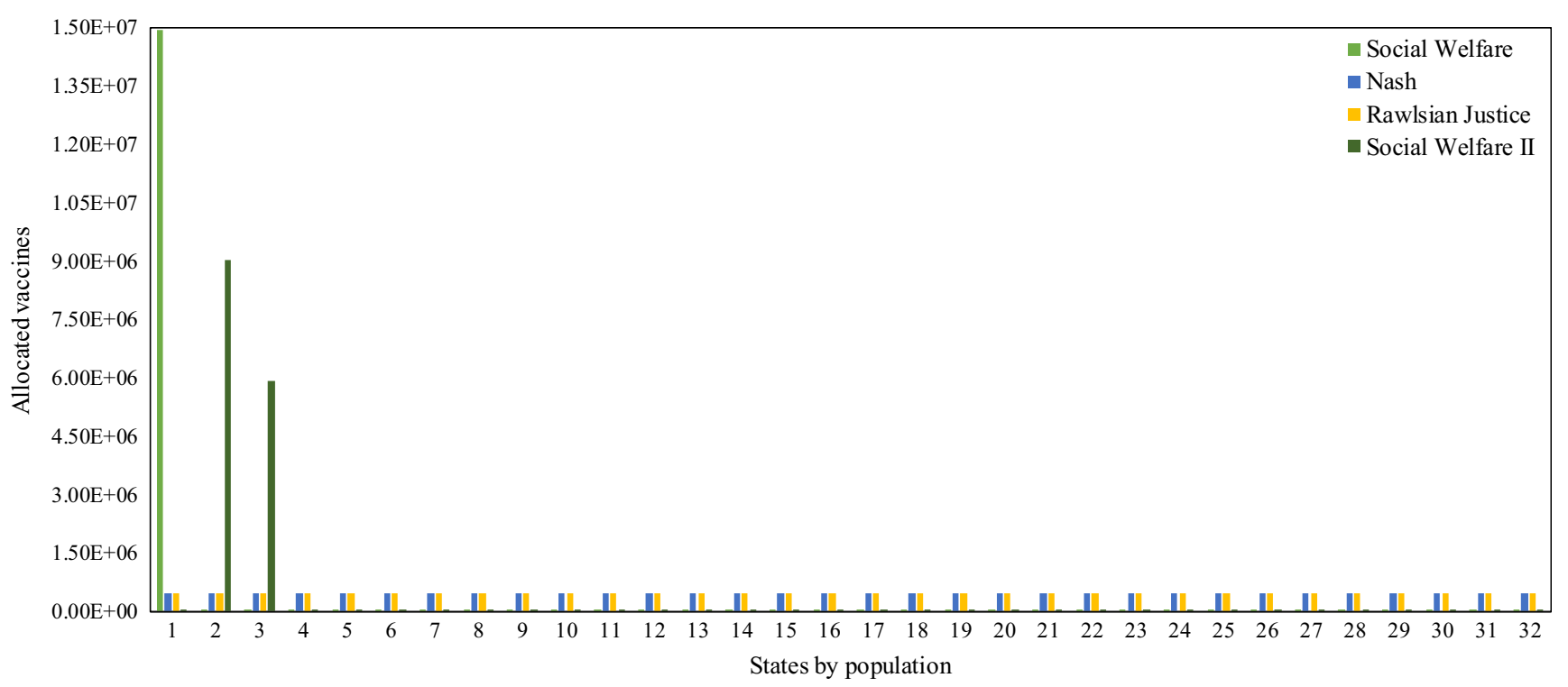

Fig. 5 Allocated vaccines under different allocation schemes (scenario (d) of availability)

are allocated (equal to its population). The rest is allocated to state 4 . The social welfare II scheme favors several states. It allocates the maximum vaccines to states $6,7,10,17,18,19$, $21,22,23,24,25,26,27$, and 28 . The remaining vaccines are allocated to state 12 . As opposed to the other scenarios, the Nash and Rawlsian schemes do not provide identical allocations. We can observe that the Nash scheme allocates the same amount of vaccines to almost all the states. However, fewer vaccines are allocated to some states (29-32). This allocation occurs because the maximum vaccines for each of these states are assigned (equal to their population). The rest of the vaccines are allocated equally among the other states (1-28). On the other hand, the Rawlsian scheme favors state 1 by allocating a number of vaccines close to its maximum. In this scheme, the remaining vaccines are assigned equally among the other states (2-32). This allocation corresponds to assigning the smallest state (32) its maximum.

\section{Conclusions}

In this work, we presented an optimization formulation for the allocation of potential COVID-19 vaccines through fairness schemes. Distinct parameters to model the distribution of vaccines were considered. Specifically, the case study of Mexico was addressed. We analyzed the allocated vaccines to each state of Mexico given by the allocation schemes (social

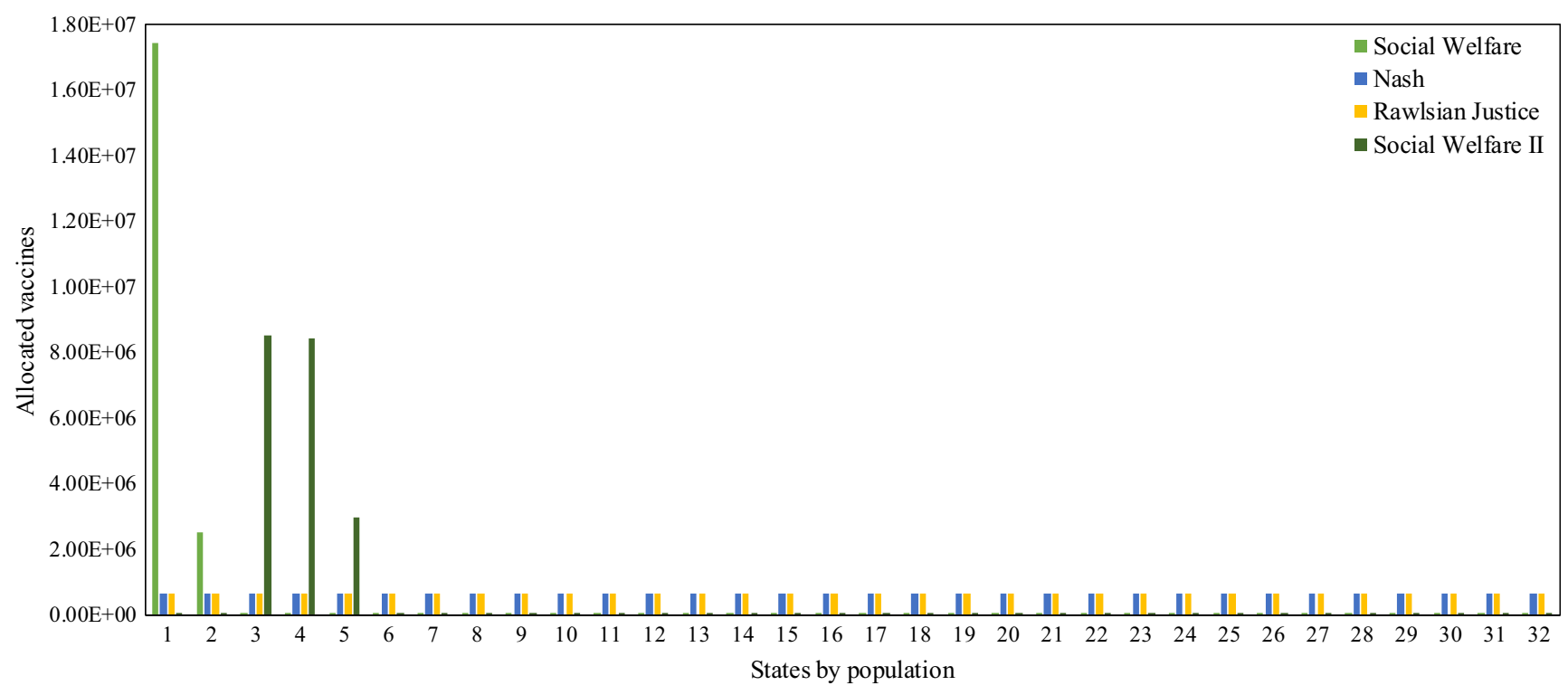

Fig. 6 Allocated vaccines under different allocation schemes (scenario (e) of availability) 


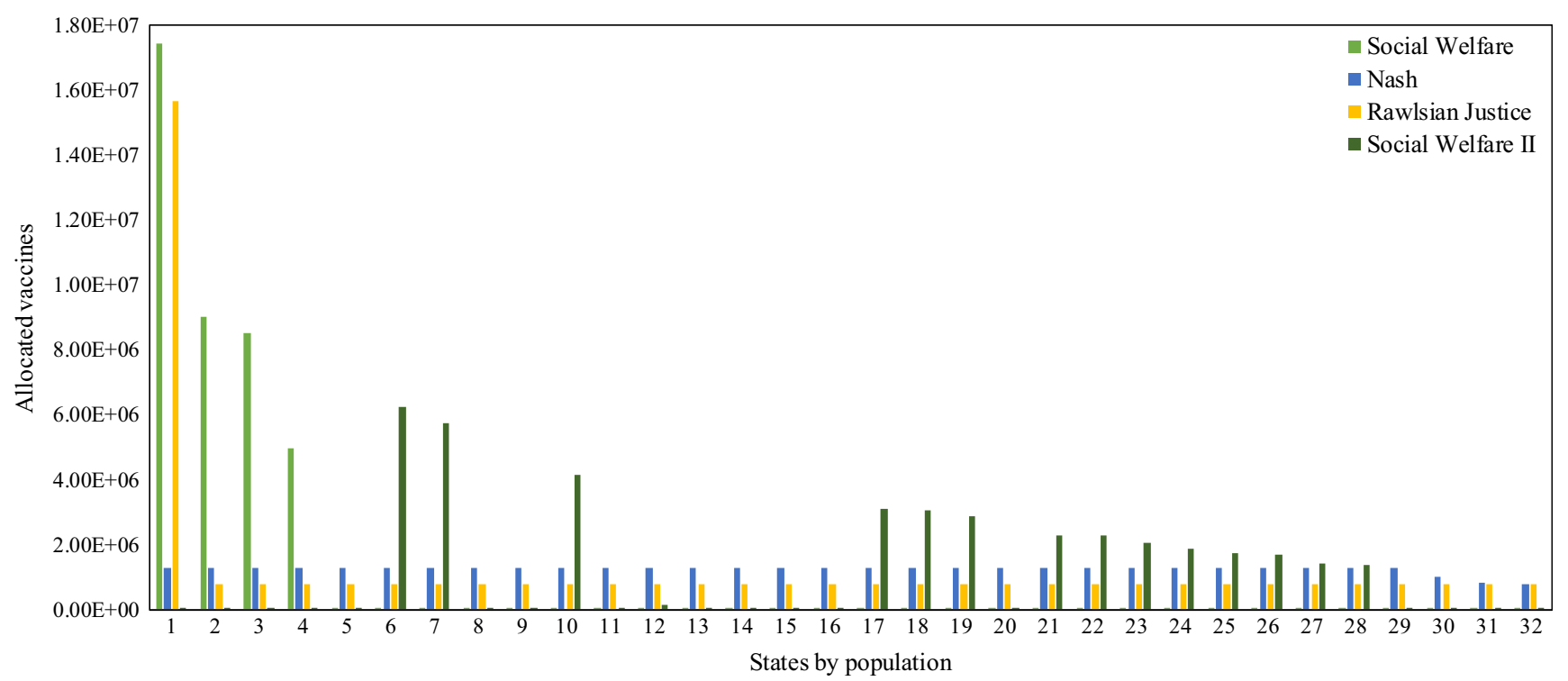

Fig. 7 Allocated vaccines under different allocation schemes (scenario (f) of availability)

welfare, Nash, Rawlsian justice, and social welfare II scheme) under different availability scenarios. We observe that the allocation of resources is a complex problem that can result in unfair distributions if it is not addressed properly. Mainly, when several stakeholders (32 states in our case study) are involved, the possible assignations are greater. We also observe that inequalities become critical when resources are scarce. For example, in scenario (b), where the social welfare approaches (standard and II) give preference only to one particular state by depriving the others. Specifically, the first solution obtained by the social welfare approach (standard) tends to favor large stakeholders (greater population) in all scenarios. On the other hand, when the available vaccines are greater, the complexity of the allocation increases since the possible solutions increase as well (such as in scenario (d)). Therefore, it is critical to consider all the possible allocations that the fairness schemes provide to identify the most suitable solution.

Funding The authors want to thank CONACyT and CIC-UMSNH for the financial support.

Nomenclature Parameters $b_{s}$, DEMAND for hospital beds for COVID-19 patients that cannot be satisfied; $b_{s}^{\text {ho }}$, available beds in each state $s$ for all diseases; $c_{s}$, threshold of each state $s$ (refers to the minimum amount of population that should receive a vaccine); $d_{s}^{\mathrm{p}}$, discharged patients in each state $s$ per year for all diseases; $d^{\mathrm{y}}$, days in the year; $f_{s}^{\mathrm{dm}}$, prevalence of diagnosed diabetes mellitus in adults in each state $s ; f_{s}^{e}$, fraction of elderly population in each state $s ; f^{\mathrm{h}}$, Fraction of COVID-19 patients who require hospitalization; $f_{s}^{\text {hy }}$, prevalence of hypertension in adults in each state $s ; f_{s}^{\text {ob }}$, prevalence of obesity in adults in each state $s ; i^{\text {o }}$, occupancy index; $m_{s}$, COVID-19 mortality rate; $m^{\mathrm{dm}}$, mortality of COVID-19 patients with diabetes mellitus; $m^{\mathrm{e}}$, mortality of elderly patients with COVID-19; $m^{\text {hy }}$, mortality of COVID-19 patients with hypertension; $m^{\mathrm{ob}}$, mortality of COVID-19 patients with obesity; $p_{s}$, population of each state $s ; r_{s}$, rate of COVID-19 cases of each state $s ; s_{s}^{\text {a }}$, average stay in days of patients in each state $s$ for all diseases; $v_{s}^{\mathrm{SW}}$, allocated vaccines to each state $s$ by the social welfare scheme; VT, total available vaccines

Variables $v_{s}$, allocated vaccines to each state $s ; \sigma^{\mathrm{N}}$, variable to denote the objective function in the Nash scheme; $\sigma^{\mathrm{R}}$, variable to denote the objective function in the Rawlsian justice scheme; $\sigma^{\mathrm{sw}}$, variable to denote the objective function in the social welfare scheme; $\sigma^{\text {SII }}$, variable to denote the objective function in the social welfare II scheme

\section{References}

Acuna JA, Zayas-Castro JL, Charkhgard H (2020) Ambulance allocation optimization model for the overcrowding problem in US emergency departments: a case study in Florida. Socio-Econ Plan Sci 71: 100747. https://doi.org/10.1016/j.seps.2019.100747

Aviso KB, Cayamanda CD, Mayol AP, Yu KDS (2017) Optimizing human resource allocation in organizations during crisis conditions: a P-graph approach. Process Integr Optim Sustain 1:59-68. https:// doi.org/10.1007/s41660-017-0004-3

Barquera S, Campos-Nonato I, Hernández-Barrera L, Villalpando S, Rodríguez-Gilabert C, Durazo-Arvizú R, Aguilar-Salinas CA (2010) Hypertension in Mexican adults: results from the National Health and Nutrition Survey 2006. Salud Publica Mex 52:S63-S71. https://doi.org/10.1590/s0036-36342010000700010

Barquera S, Campos-Nonato I, Hernandez-Barrera L, Pedroza A, RiveraDommarco JA (2013) Prevalence of obesity in Mexican adults 2000-2012. Salud Publica Mex 55:S151-S160

Bassi LL, Hwenda L (2020) COVID-19: time to plan for prompt universal access to diagnostics and treatments. Lancet Glob Health 8(6): e756-e757. https://doi.org/10.1016/S2214-109X(20)30137-6

Bollyky TJ, Gostin LO, Hamburg MA (2020) The equitable distribution of COVID-19 therapeutics and vaccines. JAMA. 323(24):24622463. https://doi.org/10.1001/jama.2020.6641

DGE (2020) Covid-19 Mexico. https://coronavirus.gob.mx/datos/\# DOView (accessed April 30, 2020) 
Emanuel EJ, Persad G, Upshur R, Thome B, Parker M, Glickman A, Zhang C, Boyle C, Smith M, Phillips JP (2020) Fair allocation of scarce medical resources in the time of Covid-19. N Engl J Med 382: 2049-2055. https://doi.org/10.1056/NEJMsb2005114

Garg I, Srivastava S, Rai C, Kumar V, Hembrom AA, Ghosh N, Kumari B, Bansal A, Kumar B (2020) Coronavirus (COVID-19): prognostic risk associated with comorbidities and age. Int J Recent Sci Res 11(04):37983-37986. https://doi.org/10.24327/ijrsr.2020.1104. 5218

Hernández-Ávila M, Gutiérrez JP, Reynoso-Noverón N (2013) Diabetes mellitus en México: El estado de la epidemia. Salud Publica Mex 55: s129-s136. https://doi.org/10.21149/spm.v55s2.5108

INEGI (2014) Perfil Socio-demográfico de adultos mayores. Mexico, 2014. http://internet.contenidos.inegi.org.mx/contenidos/Productos/ prod_serv/contenidos/espanol/bvinegi/productos/censos/poblacion/ 2010/perfil_socio/adultos/702825056643.pdf" (accessed May 1, 2020)

Juárez-García M, Munguía-López AC, Ponce-Ortega JM (2020) Optimization approach to identify fair solutions in the synthesis of carbon, hydrogen, and oxygen symbiosis networks. Ind Eng Chem Res 59(13):5985-5995. https://doi.org/10.1021/acs.iecr.9b06993

Khamsi R (2020) If a coronavirus vaccine arrives, can the world make enough. Nature 580(7805):578-580. https://doi.org/10.1038/ d41586-020-01063-8

Lazcano-Ponce E, Alpuche-Aranda C (2020) Alfabetización en salud pública ante la emergencia de la pandemia por Covid-19. Salud Publica Mex 62(3):331-340. https://doi.org/10.21149/11408

Le TT, Andreadakis Z, Kumar A, Roman RG, Tollefsen S, Saville M, Mayhew S (2020) The COVID-19 vaccine development landscape. Nat Rev Drug Discov 19:305-306. https://doi.org/10.1038/d41573020-00073-5

Li W, Shi Z, Yu M, Ren W, Smith C, Epstein JH, Wang H, Crameri G, $\mathrm{Hu}$ Z, Zhang H, Zhang J (2005) Bats are natural reservoirs of SARSlike coronaviruses. Science 310(5748):676-679. https://doi.org/10. 1126/science.1118391

Liu K, Chen Y, Lin R, Han K (2020) Clinical features of COVID-19 in elderly patients: a comparison with young and middle-aged patients. J Inf Secur 80(6):e14-e18. https://doi.org/10.1016/j.jinf.2020.03. 005

Mahase E (2020) Covid-19: what do we know so far about a vaccine? BMJ 369:m1679. https://doi.org/10.1136/bmj.m1679

Manca D, Caldiroli D, Storti E (2020) A simplified math approach to predict ICU beds and mortality rate for hospital emergency planning under Covid-19 pandemic. Comput Chem Eng 140:106945. https:// doi.org/10.1016/j.compchemeng.2020.106945

Mendoza-Alonzo J, Zayas-Castro J, Charkhgard H (2020) Office-based and home-care for older adults in primary care: a comparative analysis using the Nash bargaining solution. Socio-Econ Plan Sci 69: 100710. https://doi.org/10.1016/j.seps.2019.05.001

Munguía-López AC, Sampat AM, Rubio-Castro E, Ponce-Ortega JM, Zavala VM (2019) Fairness-guided design of water distribution networks for agricultural lands. Comput Chem Eng 130:106547. https://doi.org/10.1016/j.compchemeng.2019.106547

Nash JF Jr (1950) The bargaining problem. Econometrica 18(2):155-162 DOI: 0012-9682(195004)18:2<155:TBP $>2.0 . \mathrm{CO} ; 2-\mathrm{H}$

Persad G, Wertheimer A, Emanuel EJ (2009) Principles for allocation of scarce medical interventions. Lancet 373(9661):423-431. https:// doi.org/10.1016/S0140-6736(09)60137-9

Phelan AL (2020) COVID-19 immunity passports and vaccination certificates: scientific, equitable, and legal challenges. Lancet 395(10237):1595-1598. https://doi.org/10.1016/S0140-6736(20) 31034-5
Quesada E (2009) Cantidad, uso y gestión de las camas hospitalarias, tendencias en el mundo y situación en Mendoza. https://isg.org.ar/ wp-content/uploads/2011/12/Gestion-camas-hospitalarias-ISG.pdf (accessed April 25, 2020)

Rawls J (1971) A theory of justice. Harvard Univ. Press, Cambridge

Sampat AM, Zavala VM (2019) Fairness measures for decision-making and conflict resolution. Optim Eng 20(4):1249-1272. https://doi. org/10.1007/s11081-019-09452-3

Savachkin A, Uribe A (2012) Dynamic redistribution of mitigation resources during influenza pandemics. Socio-Econ Plan Sci 46(1):3345. https://doi.org/10.1016/j.seps.2011.05.001

SINAISCAP (2020) Sistema de información de la secretaria de salud. http://sinaiscap.salud.gob.mx:8080/DGIS/\# (accessed April 30, 2020)

Sy C, Bernardo E, Miguel A, San Juan JL, Mayol AP, Ching PM, Culaba A, Ubando A, Mutuc JE (2020) Policy development for pandemic response using system dynamics: a case study on COVID-19. Process Integr Optim Sustain 4:497-501. https://doi.org/10.1007/ s41660-020-00130-x

Torres Ramírez C (2020) Covid-19. Seguimiento de la pandemia (III). Mexico. http://bibliodigitalibd.senado.gob.mx/bitstream/handle/ 123456789/4841/NE_84_Seguimiento\%20Pandemia\%20III\% 20vf.pdf?sequence $=1 \&$ isAllowed=y" (accessed April 25, 2020)

UISP (2020) Tablero interactivo sobre COVID-19. https://www.insp.mx/ informacion-institucional-covid-19.html (accessed April 30, 2020)

Vergano M, Bertolini G, Giannini A, Gristina GR, Livigni S, Mistraletti G, Riccioni L, Petrini F (2020) Clinical ethics recommendations for the allocation of intensive care treatments in exceptional, resourcelimited circumstances: the Italian perspective during the COVID-19 epidemic. Crit Care 24:165. https://doi.org/10.1186/s13054-02002891-w

Wang N, Li SY, Yang XL, Huang HM, Zhang YJ, Guo H, Luo CM, Miller M, Zhu G, Chmura AA, Hagan E (2018) Serological evidence of bat SARS-related coronavirus infection in humans, China. Virol Sin 33(1):104-107. https://doi.org/10.1007/s12250018-0012-7

WHO (2020a) WHO Director-General's remarks at the media briefing on 2019-nCoV on 11 February 2020. https://www.who.int/dg/ speeches/detail/who-director-general-s-remarks-at-the-mediabriefing-on-2019-ncov-on-11-february-2020 (accessed May 4, 2020)

WHO (2020b) Q\&A on coronaviruses (COVID-19). What are the symptoms of COVID-19? https://www.who.int/emergencies/diseases/ novel-coronavirus-2019/question-and-answers-hub/q-a-detail/q-acoronaviruses (accessed May 11, 2020)

Wu Z, McGoogan JM (2020) Characteristics of and important lessons from the coronavirus disease 2019 (COVID-19) outbreak in China: summary of a report of 72314 cases from the Chinese Center for Disease Control and Prevention. JAMA 323(13):1239-1242. https://doi.org/10.1001/jama.2020.2648

Zavala VM, Kim K, Anitescu M, Birge J (2017) A stochastic electricity market clearing formulation with consistent pricing properties. Oper Res 65(3):557-576. https://doi.org/10.1287/opre.2016.1576

Zhou P, Yang XL, Wang XG, Hu B, Zhang L, Zhang W, Si HR, Zhu Y, Li B, Huang CL, Chen HD (2020) A pneumonia outbreak associated with a new coronavirus of probable bat origin. Nature 579(7798): 270-273. https://doi.org/10.1038/s41586-020-2012-7

Publisher's Note Springer Nature remains neutral with regard to jurisdictional claims in published maps and institutional affiliations. 